\title{
Accounting for effects of carbon flows in LCA of biomass-based products-exploration and evaluation of a selection of existing methods
}

\author{
Christin Liptow $^{1} \cdot$ Matty Janssen ${ }^{1}$ (D) $\cdot$ Anne-Marie Tillman ${ }^{1}$
}

Received: 16 May 2016 / Accepted: 1 January 2018 / Published online: 22 January 2018

(C) The Author(s) 2018. This article is an open access publication

\begin{abstract}
Purpose Life cycle assessment (LCA) has become one of the most widespread environmental assessment tools during the last two decades. However, there are still impacts that are not yet fully integrated, including climate impacts of land use. This study contributes to the development process by testing a selection of recently proposed climate impacts assessment methods, some more focused on the impact of land use and others more focused on a product's carbon life cycle.

Methods Several assessment methods have been proposed in recent years, with their development still being in progress. Of these methods, we selected three methods that are more focused on the product's carbon life cycle, and two methods more focused on the impact of land use. We applied the methods to an LCA study comparing biomass-based polyethylene (PE) packaging via different production routes in order to identify their methodological and practical challenges.

Results and discussion We found that including the impact of land use and carbon cycles had a profound effect on the results for global warming impact potential. It changed the ranking among the different routes for PE production, sometimes making biomass-based PE worse than the fossil alternative. Especially, the methods accounting for long time lags between carbon emissions and uptake in forestry punished the wood-based routes. Moreover, the variation in the results was considerable, showing that although assessment methods for climate impact can be applied to biomass-based products, their outcomes are not yet robust.

Conclusions We recommend efforts to harmonize and reconcile different approaches for the assessment of climate impact of biomass-based products with regard to (1) how they consider time, (2) their applicability to both short and long rotation crops and (3) harmonization of concepts and terms used by the methods. We further recommend that all value laden methodological choices that are built into the methods, such as the choice of reference states/points, are made explicit and that the outcomes of different modelling choices are tested.
\end{abstract}

Keywords Carbon cycle $\cdot$ Global warming $\cdot$ Land use $\cdot$ Life cycle assessment $\cdot$ Polyethylene $(\mathrm{PE}) \cdot$ Time lags

\section{Introduction}

Throughout history, biomass has been used for feed, food, material and fuel purposes and over its course, plants,

Responsible editor: Yi Yang

Matty Janssen

mathias.janssen@chalmers.se

1 Division of Environmental Systems Analysis, Department of Energy and Environment, Chalmers University of Technology, SE-412 96 Goteborg, Sweden landscapes and cultivation techniques have been altered in order to systematically and steadily produce more biomassbased products. These changes have not always been without significant consequences, not only for the environment that they are introduced into but also for the people living in this environment (European Environment Agency 2012). More recently, environmental systems analysis tools have been developed to assess these environmental consequences. This includes life cycle assessment (LCA), which accounts for the environmentally relevant inputs to and outputs from a product's life cycle from cradle-to-grave and which quantifies the resulting potential environmental impact (International Organization of Standardization 2006). 
LCA has become one of the most widespread environmental systems analysis tools and has been used for the assessment of a considerable range of biomass-based products, such as food products, biofuels and biomaterials. However, when examining LCA studies of such products more closely, it becomes clear that for the biomass acquisition phase, only certain environmentally relevant flows, such as fertilizer and pesticide production and use or fuel use in machinery, and their related impacts are considered. Quantifying other types of impacts related to biomass cultivation and land use, such as impact on biodiversity or the effect on carbon balances, has been more problematic. While there are some examples of method development regarding, for example, impact on biodiversity (see, e.g. de Baan et al. (2013), de Baan et al. (2015), Geyer et al. (2010a, b)), these methods have not yet been applied to a significant extent. Nevertheless, the development of methods to account for impacts related to land use in LCA, global warming impacts specifically, has intensified in recent years, partly spurred by the debate about climate change. It appears that this development has taken place along different research streams, which are only partly related.

Within the LCA community, a framework for the assessment of the environmental impact from land use was developed and published as the UNEP-SETAC guideline on global land use impact assessment (Koellner et al. 2013). This guideline, which builds on the framework developed by Milà et al. (2007), covers the assessment of impacts of direct land occupation (also called land use) and land transformation (also called land use change) on biodiversity and ecosystem services, including climate regulation. An important assumption used in this guideline is that during occupation the quality of the land stays constant (e.g. the carbon content of the soil stays the same over the time of occupation), although this is not necessarily true (see, e.g. Anderson-Teixeira et al. (2009) for the case of sugar cane in Brazil). With regard to land transformation, only the effects of direct land use changes are accounted for in the guideline, while indirect effects are considered beyond its scope. The method development for assessing indirect land use change (e.g. Kløverpris and Mueller (2013), Schmidt et al. (2015)) seems to have evolved in parallel to the UNEPSETAC guideline (Koellner et al. 2013), rather than directly from it. The methods developed in conjunction with the UNEP-SETAC guideline on global land use impact assessment are referred to as land use methods in this paper.

In order to account for the potential impact of long growth periods (and thus for long periods of land occupation) and related time lags in the carbon cycle of wood and related products, various methods have been suggested by, e.g. Cherubini et al. (2011a), Pingoud et al. (2012) and Pingoud et al. (2015) in a research stream which seems to be rather disconnected from the one leading up to the UNEP-SETAC guideline (Koellner et al. 2013). These methods are referred to as carbon cycle methods in this paper.

Although work on method development is currently intense, there still seems to be a rather long way to go before methods for the impact assessment related to land use and time lags in the carbon cycle are ready to be routinely used in LCA studies. This is partly due to the theoretical focus of current review and meta-studies (e.g. Agostini et al. (2013), Goglio et al. (2015), Helin et al. (2013), Lamers and Junginger (2013), Lindeijer (2000)). Moreover, the relatively small number of case studies that actually test proposed methods (e.g. Cintas et al. (2015), Helin et al. (2014), Koponen and Soimakallio (2015), Milà et al. (2013), Muñoz et al. (2014)) implies that LCA practitioners are not familiar with these methods yet and that they are thus not in wide-spread use.

The purpose of this study therefore is to test different methods for the assessment of global warming due to land use, excluding indirect LUC, and the potential effect of time lags in the carbon cycle, in order to provide further insights with regard to their methodological challenges and to give recommendations for further development. In addition, more practical aspects such as data availability, method acceptance and ease of application were considered. The production of bio-based polyethylene (PE) from wood, via fermentation and gasification, and sugarcane, via fermentation, is used as a LCA case study.

\section{Materials and methods}

\subsection{Description of the system under study}

The case study used for testing the different methods was packaging made from polyethylene (PE) based on biomass. Specifically, polyethylene produced from wood (from Swedish boreal forest) and from sugarcane (from Brazil) was considered (see Fig. 1). In total, three PE production routes were included: (1) two different hypothetical routes from wood to PE, via fermentation to ethanol followed by dehydration to ethylene and via gasification yielding syngas that is converted to methanol and subsequently to ethylene and (2) one existing route from sugarcane to PE, via fermentation to ethanol followed by dehydration to ethylene. The end-of-life scenario applied was incineration, i.e. complete oxidation of the PE packaging. All three routes were investigated in a series of preceding papers (Liptow and Tillman 2012, Liptow et al. (2015), Liptow et al. (2013)). These three studies included inventory data for biogenic $\mathrm{CO}_{2}$ emissions, that is, $\mathrm{CO}_{2}$ emissions originating from biomass, and were used as a database to quantify emissions of fossil and biogenic $\mathrm{CO}_{2}$ in the life cycles of each case. In addition, data for the case of the fossil based PE production route were used for 

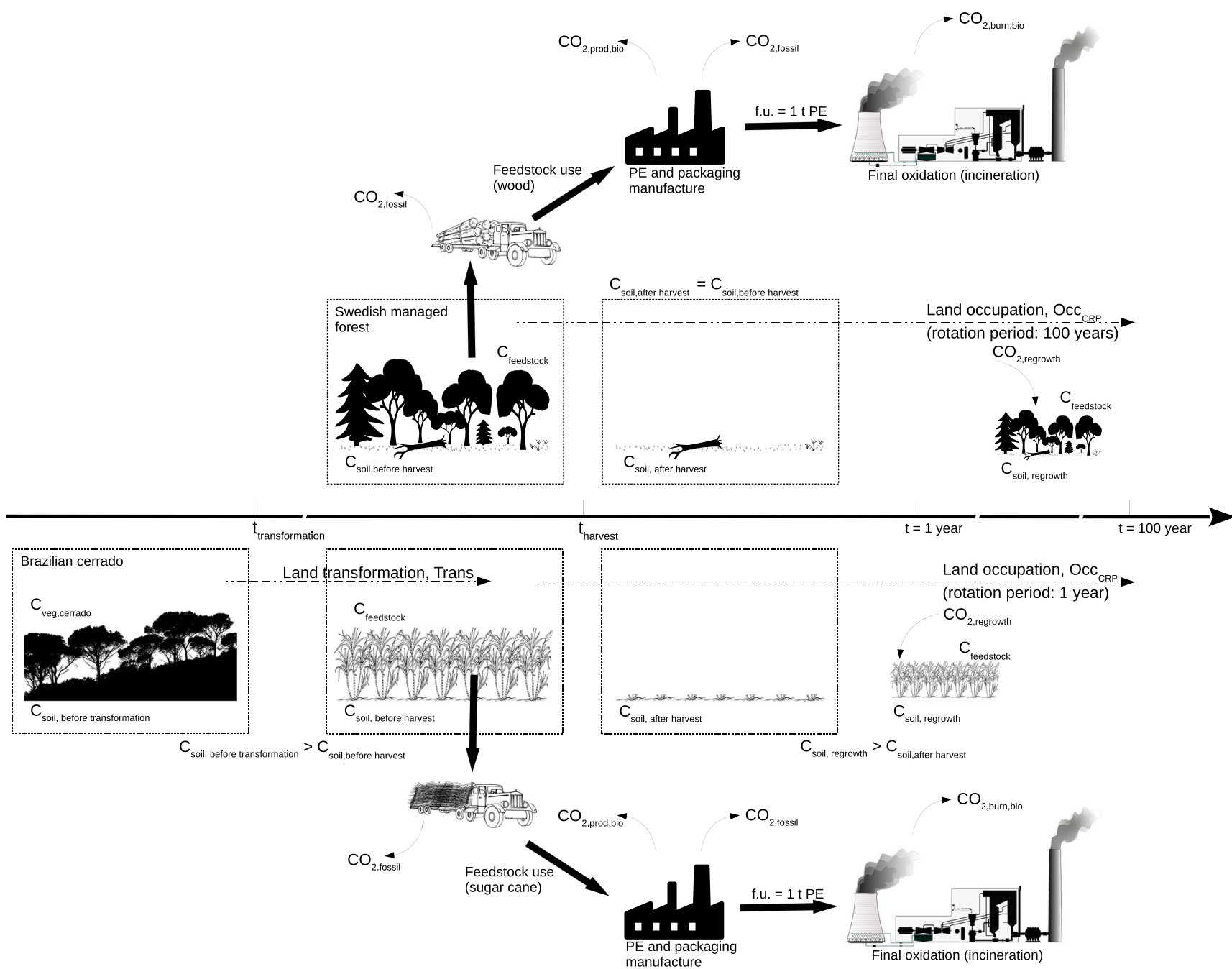

Fig. 1 Life cycle of biomass-based PE applied as packaging material. The system includes the cultivation and harvesting of the biomass (wood or sugar cane), the production of PE and the packaging thereof, and the

comparison. The selected assessment methods were then applied to these inventory data.

\subsection{Selection and description of assessment methods}

A literature review was done on methods for the assessment of global warming due to land use and biogenic $\mathrm{CO}_{2}$ emissions in LCA. There are different indicators to express the impact on global warming of biogenic carbon (see, e.g. Ericsson et al. (2013)); the review however considered methods using global warming potential (GWP) only because of its ubiquitous use compared to other indicators such as global temperature potential (GTP). Furthermore, methods that are theoretically related but not directly applicable in an LCA context (e.g. Bernier and Paré (2013), Holtsmark (2012), Zanchi et al. (2012)) were outside the scope of this study. Such methods do not provide characterization factors for the impact due to biogenic carbon waste management (incineration of the packaging). Relevant carbon flows and pools are depicted

flows, for instance, but rather focus on the variation over time of these flows. This can be considered as a part of the inventory analysis in an LCA but not as part of an impact assessment method. Also, this study only considered the attributional assessment of global warming, and therefore, methods focusing on effects of indirect land use change (iLUC) (e.g. Kløverpris and Mueller (2013), Schmidt et al. (2015)) were outside the scope of this study.

Three carbon cycle methods (see Introduction), the GWP $_{\text {bio }}$ method (Cherubini et al. 2011a), the GWP netbio method (Pingoud et al. 2012) and the WF method (Väisänen et al. 2012), were selected. Of these three methods, two $\left(\mathrm{GWP}_{\text {bio }}\right.$ and $\mathrm{GWP}_{\text {netbio }}$ methods) calculate characterization factors ( $\mathrm{CFs}$ ) for assessing the climate impact of biogenic $\mathrm{CO}_{2}$ flows. Like for any other $\mathrm{CF}$, these CFs are applied to inventory flows, in this particular case to the biogenic $\mathrm{CO}_{2}$ flows per tonne of $\mathrm{PE}$ produced (which is the functional unit used in the LCA case study 
(see Sect. 2.1)). In contrast, the WF method calculates a weighting factor (WF) which is applied to the inventoried amount of biogenic $\mathrm{CO}_{2}$ before applying the CFs commonly used for fossil $\mathrm{CO}_{2}$ in the life cycle impact assessment. The three selected methods are now described in more detail.

GWP $_{\text {bio }}$ method This method (Cherubini et al. 2011a) is currently one of the most discussed impact assessment methods (see, e.g. Holtsmark (2012) and Cintas et al. (2017)). Similar to the already used GWP characterization

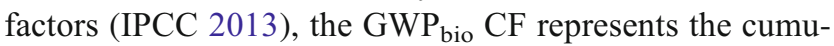
lative radiative forcing of a greenhouse gas relative to the forcing of a pulse of $\mathrm{CO}_{2}$ and thus also is a relative measure of the potential effects of that greenhouse gas on the climate. However, in contrast to the commonly used GWP CFs, a CF calculated with the $\mathrm{GWP}_{\text {bio }}$ method explicitly considers the timing of biogenic $\mathrm{CO}_{2}$ emissions and uptake during a rotation period and thus is time-dependent. A $\mathrm{GWP}_{\text {bio }} \mathrm{CF}$ is derived by assuming that (1) the $\mathrm{CO}_{2}$ that is taken up due to biomass growth is forward looking. This means that $\mathrm{CO}_{2}$ uptake is considered to occur during the re-growth of the biomass after harvest, rather than during the growth before harvest and (2) the $\mathrm{CO}_{2}$ uptake by regrowing biomass is considered at a single stand level. This means that the $\mathrm{CO}_{2}$ emitted from an oxidizing product (in the case study used (see Sect. 2.1), incineration of PE produced from wood or sugarcane) is assumed to be taken up by re-growth occurring on the same stand from which the biomass was originally harvested. A GWP ${ }_{\text {bio }} \mathrm{CF}$ is calculated with the following three steps:

1. The change in atmospheric $\mathrm{CO}_{2}$ concentration over time, due to the emission and uptake of $\mathrm{CO}_{2}$, is calculated. This is done by combining the difference of emission and uptake of $\mathrm{CO}_{2}$ with a function that represents the decay of $\mathrm{CO}_{2}$ in the atmosphere via the removal of $\mathrm{CO}_{2}$ by the ocean and terrestrial biosphere sinks (Cherubini et al. 2011b).

2. The change in this concentration is then used to calculate the absolute global warming potential ( $\mathrm{AGWP}_{\mathrm{bio}}$ ) for the time horizon under assessment. $\mathrm{AGWP}_{\mathrm{bio}}$ is defined as the cumulative radiative forcing of the biogenic $\mathrm{CO}_{2}$ and measures the absolute potential effect the biogenic $\mathrm{CO}_{2}$ has on the climate. It is calculated in two steps: (a) the change in atmospheric concentration of $\mathrm{CO}_{2}$ is multiplied with the radiative efficiency of $\mathrm{CO}_{2}$, and (b) this product is then integrated over the time horizon that is applied in the method (e.g. 100 years).

3. The $\mathrm{GWP}_{\text {bio }} \mathrm{CF}$ is then calculated by dividing the $\mathrm{AGWP}_{\text {bio }}$ with the AGWP of a $\mathrm{CO}_{2}$ pulse, and thus becomes a relative measure.
GWP $_{\text {netbio }}$ method This method (Pingoud et al. 2012) is similar to the $\mathrm{GWP}_{\text {bio }}$ method and is based on the same core assumptions regarding $\mathrm{CO}_{2}$ uptake. In addition, it considers the potential impact from lost uptake, i.e. the uptake if the trees had been left standing, and had continued to grow and take up $\mathrm{CO}_{2}$ from the atmosphere. This continued growth may be interpreted as relaxation to a 'natural' state, and the absence thereof could thus be interpreted as a kind of land occupation impact, as done by Helin et al. (2014). Furthermore, the method considers avoided burdens, which are displaced fossil emissions if the same product had been produced from a fossil resource.

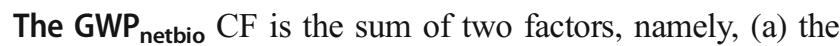
$\mathrm{GWP}_{\text {bio }} \mathrm{CF}$, which considers the change in carbon stocks in the forest stand due to biomass harvest and re-growth, as well as lost uptake (note that this is not the same $\mathrm{GWP}_{\text {bio }}$ as defined by the $\mathrm{GWP}_{\text {bio }}$ method by Cherubini et al. (2011a)), and (b) the $\mathrm{GWP}_{\text {biouse }} \mathrm{CF}$, which considers the abovementioned avoided burdens and the $\mathrm{CO}_{2}$ emissions from the biomassbased product and their timing (in the case study used (see Sect. 2.1), incineration of PE produced from wood or sugarcane). Both factors are determined via the same procedure already described for Cherubini's $\mathrm{GWP}_{\text {bio }} \mathrm{CF}$. As pointed out by Helin et al. (2013), the modelling of avoided burdens is usually done in the inventory phase of LCA, but in this method, it is included in the impact assessment.

WF method The underlying core assumptions of the WF (weighting factor) method (Väisänen et al. 2012) with respect to $\mathrm{CO}_{2}$ uptake are similar to those of the $\mathrm{GWP}_{\text {bio }}$ method, but it models the uptake with a simple linear function. Furthermore, Väisänen et al. (2012) do not explicitly take into account the timing of emissions but instead assume that all $\mathrm{CO}_{2}$ emissions occur as a pulse at the time of harvest. This is considered as a carbon debt, which is paid back by the re-growing biomass. The WF is determined by calculating the proportion of the total carbon uptake due to biomass re-growth at every time step, summing up these proportions over the assessment period considered, and finally dividing the sum by the assessment period (e.g. 100 years). Based on the determined WF, the fraction of carbon released into the atmosphere is calculated. Finally, the average $\mathrm{CO}_{2}$ emission due to biomass harvest is derived by multiplying the amount of $\mathrm{C}$ (as $\mathrm{CO}_{2}$ ) harvested with the determined WF. While the $\mathrm{GWP}_{\text {bio }}$ and $\mathrm{GWP}_{\text {netbio }}$ methods determine a characterization factor, the WF method thus provides an inventory factor that is multiplied with the inventoried amount of biogenic $\mathrm{CO}_{2}$. The resulting amounts of $\mathrm{CO}_{2}$, together with the $\mathrm{CO}_{2}$ emissions during other life cycle stages such as transport and harvesting, are then multiplied by the established $\mathrm{CO}_{2}$ GWP characterization factor (IPCC 2013). 
Two land use methods (see Introduction), the GWP method (Brandão et al. 2011) and the CRP (Climate Regulation Potential) method (Müller-Wenk and Brandão 2010), were selected. The CRP method aims at assessing climate impacts due to land use by considering carbon transfer between soil and vegetation and the air. The GWP soil method only includes the changes in soil organic carbon due to land use in the calculation of the impact thereof.

The two selected methods are in accordance with the framework for land use impact assessment within LCA, described by Milà (Milà et al. 2007). The framework focuses on impacts due to changes in land quality on the natural environment (biodiversity, ecological soil quality) and on natural resources (biotic production, climate regulation, substance cycling and buffer capacity). It divides land use into land transformation (sometimes referred to as land use change), i.e. the change of land area according to its dedicated purpose, and land occupation, i.e. the use of this land area without any further transformation. In order to do an assessment according to the framework, the area (how much land is used), the time (duration of occupation and relaxation processes) and the land quality must be determined (Fig. 2). Furthermore, the reference state needs to be decided on. Milà et al. (2007) suggest that if the LCA is attributional, the naturally relaxed state is an adequate reference state (i.e. the state the land will return to if not being used any longer) (indicated with $Q_{\text {rel }}$ in Fig. 2), while if the LCA is consequential, then changes in land use with respect to an alternative system are considered and this alternative system may be used as the reference state. This means that in the case of an attributional LCA, the method defines the reference state, whereas in the case of a consequential LCA, the analyst needs to determine this state. The recently published UNEP-SETAC guideline on land use impact assessment on biodiversity and ecosystem services also uses the key elements of this framework (Koellner et al. 2013). The two selected land use methods are now described in more detail.

GWP $_{\text {soil }}$ method This method includes changes in soil organic carbon due to land use in the assessment of the global warming potential and clearly differentiates between the impact from land occupation and transformation. The method was presented as part of a case study that compared the cultivation of four energy crops (Brandão et al. 2011). In this study, all land transformations were allocated to the 100 years of subsequent occupation, while assuming that the transformation took place more than 100 years ago. Thus, the land transformation impacts no longer played a role in the assessment. As a consequence, a description on how to calculate the impact due to land transformation with the $\mathrm{GWP}_{\text {soil }}$ method is missing. Regarding the impact of land occupation, the carbon stock change during occupation is directly calculated from the carbon sequestration rate (whether positive or negative) in soil (via the carbon uptake by plants) during 1 year of a particular land occupation and is expressed in tonnes of $\mathrm{C}$. In order to assess the related climate impact, this amount of $\mathrm{C}$ is converted to tonnes of $\mathrm{CO}_{2, \text { eq }}$ using the characterization factor $3.67 \mathrm{t} \mathrm{CO}_{2, \mathrm{eq}} / \mathrm{t} \mathrm{C}$. The latter is the stoichiometric conversion factor from carbon to $\mathrm{CO}_{2}$, which is also used for fossil based carbon. This implies that the method equals biogenic carbon from soil with carbon of fossil origin.

CRP method Climate regulation potential (CRP) can be defined as the foregone sequestration of carbon due to land use, i.e. carbon that is not stored, compared to a reference land use (Milà et al. 2013). The CRP method takes into account changes in below and above ground carbon stocks (i.e. organic carbon in soil and in vegetation) due to both land occupation and transformation (Müller-Wenk and Brandão 2010). These changes are determined with respect to a reference state, which might either be the historical natural $\left(Q_{\text {his }}\right.$ in Fig. 2) or a future relaxed state $\left(Q_{\text {rel }}\right.$ in Fig. 2). The method provides no guidance in this respect. The method calculates characterization factors (CFs) for land occupation and transformation, expressed as t $\mathrm{CO}_{2, \text { eq }} /$ ha year and $\mathrm{C}_{2, \mathrm{eq}} /$ ha, respectively. These CFs are calculated by multiplying the emissions of biogenic carbon per surface area due to changes in the carbon stocks with a so-called duration factor. The main difference between determining the CFs for occupation and transformation is how this duration factor is calculated. It is defined as the ratio of the average stay of biogenic carbon in air and the average stay of fossil carbon in air, which is assumed to be 157 years (calculated with an arbitrary time horizon of 500 years). In the case of land transformation, the average stay of biogenic carbon in air is determined as $50 \%$ of the relaxation time (i.e. the time it takes for the land to arrive at the reference state), because "the mean carbon stay in air is approximately the average between zero years and the number of years required for complete relaxation" (Müller-Wenk and Brandão 2010).

In the case of land occupation, the average stay of carbon in air reflects the delay of relaxation (due to the occupation of the land) by 1 year and is thus set to be 1 year. The resulting duration factor thus is $1 / 157$ for all types of occupation. Next, the CFs are multiplied with the inventory flows of land occupation, expressed in ha year, and transformation, expressed in ha. Finally, The CRP due to land use is calculated as the sum of the CRPs due to land occupation and land transformation. It should be noted that the CRP method does not explicitly address the issue of amortizing land transformation impacts to a period of land occupation but that amortization is needed when applying the method. 
Fig. 2 Evolution of land quality ( $y$-axis) due to land use interventions for a given area over time ( $x$-axis) (adapted from Milà et al. (2007) and Koellner et al. (2013)). The land quality changes are shown as linear for simplicity's sake. It should be noted that Koellner et al. (2013) use $Q_{\text {ref, } 1}$ and $Q_{\text {ref,2 }}$ (see Fig. 2, p. 1191 ) as labels on the $y$-axis to indicate the historical land quality $\mathrm{Q}_{\text {his }}$ and the quality of the relaxed state, $\mathrm{Q}_{\mathrm{rel}}$, respectively. Furthermore, Koellner et al. (2013) assume that land quality is constant during land occupation

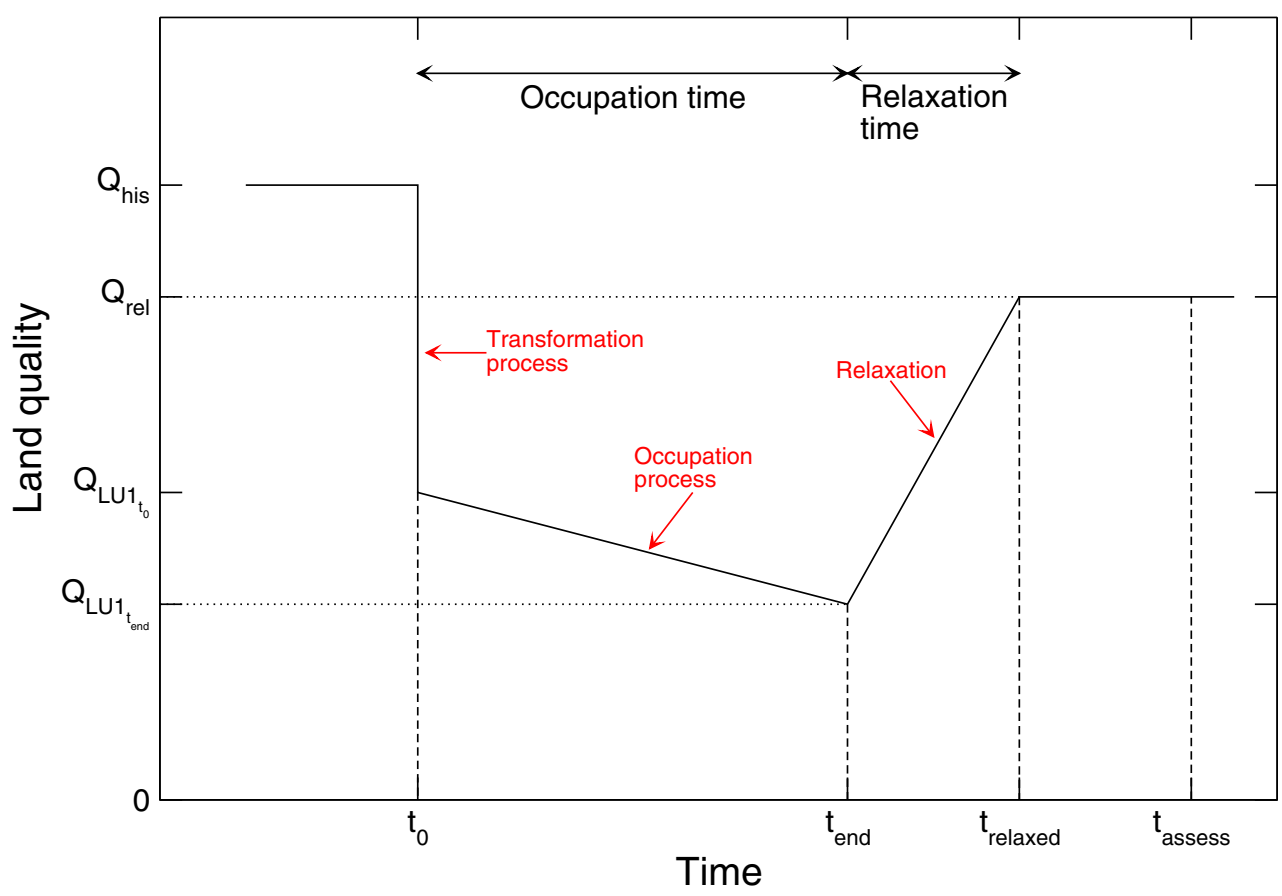

\subsection{Analysis of selected assessment methods}

The methods were analysed based on a framework developed by Helin et al. (2013) which can be summarized with the following five questions:

1. Does the method use a reference situation?

2. Does the method account for potential timing differences between emission release and uptake?

3. Does the method consider all carbon pools (above and below ground) related to the biomass system?

4. Does the method account for temporary carbon storage in biomass-based products?

5. Does the method consider product substitution effects, that is, does the method consider avoided environmental burdens due to the replacement of fossil based products?

Helin et al. (2013) stated an additional sixth question, which investigates the type of indicator used to express the climate impact of GHG emissions. However, this question was outside the scope of this study (see also Sect. 2.2). Table 1 gives a comparison of the carbon cycle and land use methods that are discussed above, using these five questions.

In addition to addressing these five method-oriented questions in the analysis, practical aspects of applying the methods were also tested. These aspects included data availability, acceptance of the method and ease of application.

\subsection{Life cycle inventory}

Table 2 presents the key inventory data used for testing the impact assessment methods, based on data from Liptow and Tillman (2012), Liptow et al. (2013) and Liptow et al. (2015). These inventory flows are also depicted in Fig. 1 (and their naming is given in Table 2). The life cycle inventory data were derived using several major modelling choices and assumptions. First of all, an attributional LCA approach was used. Next, all biogenic carbon emissions released during biomass harvest and production, and all carbon emissions related to land use, were accounted for and were assessed as $\mathrm{CO}_{2}$. In the case of sugarcane, which is cultivated in Brazil, preharvest burning was included, and in the case of wood, which originates from managed boreal forest in Sweden, the inventory for its acquisition was modified to stem wood using data from Berg and Lindholm (2005). For comparison, the $\mathrm{CO}_{2}$ emissions from a conventional fossil production route are also shown in Table 2. Furthermore, emissions from incineration of the PE (the method of disposal) were included and, for reasons of simplification, completely allocated to the PE.

As required by the tested methods, additional data were collected, e.g. on carbon stocks in soil and vegetation. These data are summarized in Table 3.

\subsection{Data and modelling choices and assumptions}

Impact assessment of sugarcane PE For the impact assessment of the sugarcane route, several additional assumptions and 
Table 1 Comparison of the carbon cycle and land use methods

\begin{tabular}{|c|c|c|c|c|c|}
\hline & \multicolumn{3}{|l|}{ Carbon cycle methods } & \multicolumn{2}{|l|}{ Land use methods } \\
\hline & $\mathrm{GWP}_{\text {bio }}$ & $\mathrm{GWP}_{\text {netbio }}$ & WF & $\mathrm{GWP}_{\text {soil }}$ & CRP \\
\hline $\begin{array}{l}\text { Does the method use a } \\
\text { reference situation? }\end{array}$ & $\begin{array}{l}\text { Yes, but reference } \\
\text { situation not } \\
\text { explicitly stated }\end{array}$ & $\begin{array}{l}\text { Yes, uses several } \\
\text { reference situations } \\
\text { that are not all } \\
\text { explicitly stated }\end{array}$ & $\begin{array}{l}\text { Yes, but reference } \\
\text { situation not } \\
\text { explicitly stated }\end{array}$ & $\begin{array}{l}\text { Yes, explicitly } \\
\text { stated }\end{array}$ & Yes, explicitly stated \\
\hline $\begin{array}{l}\text { Does the method account for } \\
\text { potential timing differences } \\
\text { between emission release } \\
\text { and uptake? }\end{array}$ & $\begin{array}{l}\text { Yes, the timing of } \\
\text { carbon release and } \\
\text { uptake is at the core } \\
\text { of the method. }\end{array}$ & $\begin{array}{l}\text { Yes, the timing of } \\
\text { carbon release and } \\
\text { uptake is at the core } \\
\text { of the method. }\end{array}$ & $\begin{array}{l}\text { Yes, but it is assumed } \\
\text { that all carbon is } \\
\text { emitted at the time } \\
\text { of harvest. }\end{array}$ & $\begin{array}{l}\text { No, but time is used } \\
\text { to distribute land } \\
\text { transformation } \\
\text { impacts. }\end{array}$ & $\begin{array}{l}\text { No, but time is } \\
\text { used to distribute } \\
\text { landtransformation } \\
\text { impacts. }\end{array}$ \\
\hline $\begin{array}{l}\text { Does the method consider all } \\
\text { carbon pools (above and } \\
\text { below ground) related to } \\
\text { the biomass system? }\end{array}$ & $\begin{array}{l}\text { No clear description, } \\
\text { seems to depend on } \\
\text { available data }\end{array}$ & $\begin{array}{l}\text { No clear description, } \\
\text { seems to depend } \\
\text { on available data }\end{array}$ & $\begin{array}{l}\text { No clear description, } \\
\text { seems to depend } \\
\text { on available data }\end{array}$ & $\begin{array}{l}\text { Below ground only } \\
\text { (soil organic } \\
\text { carbon) }\end{array}$ & $\begin{array}{l}\text { Above and below } \\
\text { ground (vegetation } \\
\text { and soil organic } \\
\text { carbon) }\end{array}$ \\
\hline $\begin{array}{l}\text { Does the method account for } \\
\text { temporary carbon storage in } \\
\text { biomass-based products? }\end{array}$ & $\begin{array}{l}\text { Yes, the timing of } \\
\text { product oxidation } \\
\text { is considered. }\end{array}$ & $\begin{array}{l}\text { Yes, the timing of } \\
\text { product oxidation } \\
\text { is considered. }\end{array}$ & $\begin{array}{l}\text { No, it is assumed } \\
\text { that all carbon is } \\
\text { emitted at the time } \\
\text { of harvest. }\end{array}$ & $\begin{array}{l}\text { No, only the impact } \\
\text { on land quality } \\
\text { due to land use } \\
\text { is included. }\end{array}$ & $\begin{array}{l}\text { No, only the impact } \\
\text { on land quality due } \\
\text { to land use is } \\
\text { included. }\end{array}$ \\
\hline $\begin{array}{l}\text { Does the method consider } \\
\text { product substitution effects? }\end{array}$ & $\begin{array}{l}\text { No, only carbon } \\
\text { uptake and release } \\
\text { due to biomass use } \\
\text { is considered. }\end{array}$ & $\begin{array}{l}\text { Yes, the method } \\
\text { considers displaced } \\
\text { emissions }\end{array}$ & $\begin{array}{l}\text { No, only carbon } \\
\text { uptake and release } \\
\text { due to biomass use } \\
\text { is considered. }\end{array}$ & $\begin{array}{l}\text { No, only changes in } \\
\text { land quality due } \\
\text { to land use are } \\
\text { considered. }\end{array}$ & $\begin{array}{l}\text { No, only changes in } \\
\text { land quality due to } \\
\text { land use are } \\
\text { considered. }\end{array}$ \\
\hline
\end{tabular}

For further details of this method comparison and for the comparison of the practical aspects, the reader is referred to the Sect. 4 of the paper

data were used, with regard to the system under analysis (see Fig. 1) and the assessment methods, respectively, and are described here.

It usually takes 12 to 18 months before a sugarcane plant can be harvested for the first time after planting (de Carvalho et al. 2004). Subsequently, the sugarcane plant is cut (harvested) every year for the next 4 years before a new one is planted (de Carvalho et al. 2004). However, for reasons of simplification, we here assumed a harvest every year, and we assumed that the carbon bound in standing sugarcane biomass before harvest is $20 \mathrm{t} \mathrm{C} /$ ha (estimate based on de Carvalho et al. (2004); similar numbers are also presented by de Figueiredo et al. (2010)) (indicated as $\mathrm{C}_{\text {feedstock }}$ in Fig. 1). The harvest is followed by the re-growth of sugarcane, which starts immediately after the harvest and which captures an amount of carbon equal to the amount of carbon harvested plus the amount of carbon burned during pre-harvest opera-

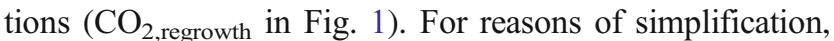
harvest and incineration of PE (oxidation of the biomassbased product, leading to biogenic $\mathrm{CO}_{2}$ emissions (indicated

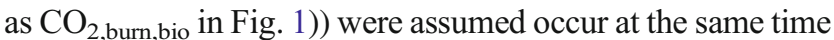
since PE packaging has a very short life span.

In the $\mathrm{GWP}_{\text {bio }}$ and $\mathrm{GWP}_{\text {netbio }}$ methods, the carbon content in the standing biomass is considered. The re-growth of the biomass was modelled using a probability density function in these methods, following Cherubini et al. (2011b). In calculating the $\mathrm{GWP}_{\text {netbio }} \mathrm{CF}$, also the replaced alternative production of the PE from a fossil feedstock is considered. For this, data for fossil $\mathrm{CO}_{2}$ emissions were used as presented in Table 2 (the related carbon flow is not depicted in Fig. 1). All three carbon cycle methods investigated include the regrowth of the biomass after harvest (indicated as $\mathrm{CO}_{2 \text {,regrowth }}$ in Fig. 1). It was assumed that the full relaxation takes 50 years in total. However, only the re-evolution (relaxation) from sugarcane cultivation to Cerrado in its first year was considered. Obeying these two assumptions and using a linear function to model the relaxation, the lost uptake during the first year of occupation is negligibly small (the lost uptake flow is not indicated in Fig. 1). For the WF method, a complete uptake occurs within 1 year after harvest and represents the re-growth of sugar cane during one rotation period.

In the $\mathrm{GWP}_{\text {soil }}$ method, only belowground carbon flows (soil organic carbon, indicated as $\mathrm{C}_{\text {soil }}$ in Fig. 1) are considered, whereas in the CRP method, also aboveground carbon flows (standing biomass, indicated as $\mathrm{C}_{\text {feedstock }}$ in Fig. 1) are considered (see Sect. 2.2). Both methods used land transformation as an inventory parameter (see Table 2). This flow was calculated based on the approach given by Milà et al. (2013). Data about land use in Brazil from 1992 until 2011 were taken from the FAO statistics website (Food and Agricultural Organization of the United Nations 2014) to assess whether land transformation should be considered, and to calculate the land transformation flow for sugarcane. These flows (expressed in ha/t PE) are different for the two methods because they do not consider the same carbon flows (see Table 2). Both methods also used land occupation as an 
Table 2 Life cycle inventory data for the biomass-based and fossil PE

\begin{tabular}{|c|c|c|c|c|c|c|}
\hline & Unit & $\begin{array}{l}\text { Sugarcane, } \\
\text { fermentation }\end{array}$ & $\begin{array}{l}\text { Wood, } \\
\text { fermentation }\end{array}$ & $\begin{array}{l}\text { Wood, } \\
\text { gasification }\end{array}$ & $\begin{array}{l}\text { Fossil } \\
\text { based }\end{array}$ & $\begin{array}{l}\text { Name in } \\
\text { Fig. } 1\end{array}$ \\
\hline Feedstock use & {$[\mathrm{t}$ dry matter/t PE] } & $12.4^{\mathrm{a}}$ & 3.8 & 5.0 & $\mathrm{n} / \mathrm{a}$ & $\mathrm{n} / \mathrm{a}$ \\
\hline $\mathrm{CO}_{2}$ uptake during growth & {$\left[\mathrm{tCO}_{2} / \mathrm{tPE}\right]$} & $18.2^{\mathrm{a}}$ & 7.0 & 9.2 & $\mathrm{n} / \mathrm{a}$ & $\mathrm{CO}_{2, \text { regrowth }}$ \\
\hline Biogenic $\mathrm{CO}_{2}$ emissions from production & {$\left[\mathrm{t} \mathrm{CO}_{2} / \mathrm{tPE}\right]$} & 15.1 & 3.9 & 6.1 & $\mathrm{n} / \mathrm{a}$ & $\mathrm{CO}_{2 \text {,prod,bio }}$ \\
\hline Biogenic $\mathrm{CO}_{2}$ emissions from final oxidation & {$\left[\mathrm{t} \mathrm{CO}_{2} / \mathrm{t} \mathrm{PE}\right]$} & 3.1 & 3.1 & 3.1 & $\mathrm{n} / \mathrm{a}$ & $\mathrm{CO}_{2 \text {,burn,bio }}$ \\
\hline Fossil $\mathrm{CO}_{2}$ emissions over life cycle & {$\left[\mathrm{t} \mathrm{CO}_{2} / \mathrm{t} \mathrm{PE}\right]$} & 1.1 & $1.4^{\mathrm{b}}$ & $0.4^{\mathrm{b}}$ & 4.4 & $\mathrm{CO}_{2, \text { fossil }}$ \\
\hline Land occupation flow, CRP & [ha.year/t PE] & 0.085 & $1.7^{\mathrm{c}}$ & $2.3^{\mathrm{c}}$ & $\mathrm{n} / \mathrm{a}$ & $\mathrm{Occ}_{\mathrm{CRP}}$ \\
\hline Land transformation flow, CRP & {$[\mathrm{ha} / \mathrm{t} \mathrm{PE}]$} & $1.3 \times 10^{-4}$ & $0^{\mathrm{d}}$ & $0^{\mathrm{d}}$ & $\mathrm{n} / \mathrm{a}$ & Trans \\
\hline Carbon flow during land occupation, $\mathrm{GWP}_{\text {soil }}$ & {$[\mathrm{t} \mathrm{C} / \mathrm{t} \mathrm{PE}]$} & 0.049 & $0^{\mathrm{e}}$ & $0^{\mathrm{e}}$ & $\mathrm{n} / \mathrm{a}$ & $\mathrm{n} / \mathrm{a}$ \\
\hline Land transformation flow, $\mathrm{GWP}_{\text {soil }}$ & {$[\mathrm{ha} / \mathrm{t} \mathrm{PE}]$} & $2.6 \times 10^{-4}$ & $0^{\mathrm{d}}$ & $0^{\mathrm{d}}$ & $\mathrm{n} / \mathrm{a}$ & Trans \\
\hline
\end{tabular}

${ }^{a}$ Includes carbon from pre-harvest burning; assumption: $100 \%$ of the trash is burned during pre-harvest operations. Carbon content in wet sugarcane is estimated to be $20 \%$ (based on data in de Carvalho Macedo et al. (2004))

${ }^{\mathrm{b}}$ Data for timber production according to Berg and Lindholm (2005); use of stem wood assumed

${ }^{\mathrm{c}}$ The land occupation flows for the wood cases are calculated based on the average above ground forest growth rate in Sweden (1.1 t C/ha year; see Table 3) and the amount of carbon needed to produce $1 \mathrm{t}$ of PE

${ }^{\mathrm{d}}$ It is assumed that in the case of forest land, transformation took place a long time ago

e There is no change in soil organic carbon content during forest growth (see also "Impact assessment of wood PE" under Sect. 2.5)

inventory parameter (see Table 2). In the case of the CRP method, this flow was calculated based on the above- and belowground carbon flows per surface area due to harvesting and the amount of carbon needed to produce $1 \mathrm{t}$ of PE (the functional unit in this study, see Fig. 1). For the calculation of the $\mathrm{GWP}_{\text {soil }}$, the carbon flow during land occupation was based on the carbon sequestration rate during sugarcane cultivation. This rate was assumed to be $0.29 \mathrm{t} \mathrm{C} /$ ha year (Anderson-Teixeira et al. 2009). The occupation and transformation flows were then multiplied with their respective characterization factors (see Sect. 2.2). Finally, we calculated the total impact due to the carbon flows as the sum of the impact during land occupation and the impact of land transformation amortized over 20 years.

Impact assessment of wood PE For the wood based routes, several additional assumptions and data were used as well during the modelling and calculations with regard to forest growth and the assessment methods, respectively, and are described here.

The forest is modelled as an even-aged boreal forest stand that is clear-cut harvested, followed by immediate re-vegetation with the same species. The rotation period of the stand is 100 years, during which the forest captures an amount of carbon equal to the amount of carbon harvested (see Fig. 1). For reasons of simplicity, harvest and incineration of PE (oxidation of the biomass-based product, leading to biogenic $\mathrm{CO}_{2}$ emissions (indicated as $\mathrm{CO}_{2}$,burn,bio in Fig. 1)) occur at the same time because PE packaging has a very short life time. For the assessment of the wood PE with the $\mathrm{GWP}_{\text {bio }}$ and $\mathrm{GWP}_{\text {netbio }}$ methods, a forestry growth model based on the Schnute growth function and its derivative was used. This equation represents an S-curve describing forest growth (see Cherubini et al. (2011a) for more details).

Cherubini et al.'s (2011a) forestry model was also used to derive data for the lost uptake to calculate the $\mathrm{GWP}_{\text {netbio }}$
Table 3 Additional data needed for the testing of the methods

\begin{tabular}{lccl}
\hline & Wood & Sugarcane & Name in Fig. 1 \\
\hline $\mathrm{C}_{100}$ in vegetation [t C/ha] & $40^{\mathrm{a}}$ & $20^{\mathrm{c}}$ & $\mathrm{n} / \mathrm{a}$ \\
$\mathrm{C}_{200}$ in vegetation [t C/ha] & $50^{\mathrm{a}}$ & $29^{\mathrm{b}}$ & $\mathrm{n} / \mathrm{a}$ \\
$\mathrm{C}$ in soil [t C/ha] & $344^{\mathrm{b}}$ & $117^{\mathrm{b}}$ & $\mathrm{C}_{\text {soil,before harvest (wood) }}$ \\
& & & $\mathrm{C}_{\text {soil, before transformation (sugar cane) }}$ \\
Annual carbon backflow [t C/ha.year] & $1.1^{\mathrm{d}}$ & $0.6^{\mathrm{b}}$ & $\mathrm{CO}_{2, \text { regrowth }}$ \\
\hline${ }^{\mathrm{a}}$ Cherubini et al. (2011a) & & & \\
${ }^{\mathrm{b}}$ Müller-Wenk and Brandão (2010) & & & \\
${ }^{\mathrm{c}}$ de Carvalho et al. (2004) & & & \\
${ }^{\mathrm{d}}$ Swedish Forest Agency (2014), based on the average forest growth rate in Sweden over 2009 to 2013
\end{tabular}


CF. For this purpose, the model was applied for a stand age of 100 to 200 years. This describes the further growth of a mature forest that is not cut down and thus represents the lost uptake (this process and the associated carbon flow is not depicted in Fig. 1). For the GWP netbio $\mathrm{CF}$ calculation, data on fossil $\mathrm{CO}_{2}$ release were used, as presented in Table 2, in order to calculate the avoided burdens of displaced fossil PE production (this flow is not shown in Fig. 1) (see Sect. 2.2). For the assessment with the WF method, growth was modelled by assuming a linear uptake of carbon by the re-growing biomass over 100 years which is a simplification when compared to the models used in the GWP $\mathrm{Gio}_{\text {bio }}$ and $\mathrm{GWP}_{\text {netbio }}$ methods for this uptake.

For the CRP and the GWP soil $_{\text {methods, it was assumed }}$ that land transformation from natural to managed forest took place long ago and that its impact is no longer of relevance (and therefore transformation of the natural to the managed forest is not depicted in Fig. 1). The land occupation flows were calculated based on the aboveground forest growth rate $(1.1 \mathrm{t} \mathrm{C} /$ ha year, see Table 3 and indicated as $\mathrm{C}_{\text {regrowth }}$ in Fig. 1) and the amount of carbon needed to produce $1 \mathrm{t}$ of PE. Furthermore, it was assumed that there is no change in the soil organic carbon content when transforming the natural forest into a managed forest and that there is no further change in this carbon stock if the forest is managed sustainably (Chen et al. 2010, De Simon et al. 2012).

\section{Results}

The results from testing the different land use and carbon cycle methods with the case studies of biomass-based PE are presented in Fig. 3, compared to the results for a fossil based $\mathrm{PE}$ route, and discussed in this section. The discussion starts with the carbon cycle methods $\left(\mathrm{GWP}_{\text {bio }}, \mathrm{GWP}_{\text {netbio }}\right.$ and WF methods), followed by the land use methods (CRP and $\mathrm{GWP}_{\text {soil }}$ methods).

Following the $\mathrm{GWP}_{\text {bio }}$ and $\mathrm{GWP}_{\text {netbio }}$ methods, the global warming impact due to biogenic $\mathrm{CO}_{2}$ emissions is calculated by applying the $\mathrm{GWP}_{\text {bio }} \mathrm{CF}$ or the $\mathrm{GWP}_{\text {netbio }} \mathrm{CF}$ to the

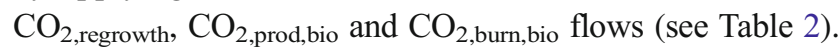
Following the WF method, the same biogenic $\mathrm{CO}_{2}$ flows are multiplied with the calculated WF and then characterized using the established $\mathrm{CO}_{2}$ GWP characterization factor (IPCC 2013) (see Sect. 2.2).

Following the CRP method, the calculated CF for land occupation is applied to the $\mathrm{Occ}_{\mathrm{CRP}}$ flow (see Table 2); the calculated CF for land transformation is applied to the Trans $_{\text {CRP }}$ flow (see Table 2) and amortized over 20 years of occupation, and both are added up to calculate the global warming impact according to this method. Following the $\mathrm{GWP}_{\text {soil }}$ method, the carbon flow during occupation (see Table 2) is multiplied with its CF (see Sect. 2.2); the land transformation flow, Trans (see Table 2), is multiplied with its CF and amortized over 20 years; and again both are added up.

\subsection{Results for the carbon cycle methods}

Considering only fossil $\mathrm{CO}_{2}$ and GHGs other than $\mathrm{CO}_{2}$ released along the life cycle (see Fig. 3, GWP ${ }_{\text {other }}$ (these values are based on the results reported in Liptow and Tillman (2012), Liptow et al. (2013) and Liptow et al. (2015)), the wood gasification route is the preferable option among the biomass and fossil routes (see Fig. 3, $\mathrm{GWP}_{\text {other }}$ and $\left.\mathrm{GWP}_{\text {fossil PE}}\right)$. However, this changes dramatically when including the results from the $\mathrm{GWP}_{\text {bio }}$ and the WF methods. Both methods assess the impact of the route's biogenic $\mathrm{CO}_{2}$ emissions to be close to the overall impact of the fossil alternative. When adding the methods' results for the impact of biogenic $\mathrm{CO}_{2}$ to the
Fig. 3 Potential impact on global warming from biogenic carbon emissions from biomass-based PE routes in the case study. This was done according to the tested methods. The total GWP per tested method is equal to the sum of the outcome of the tested method and GWP due to fossil $\mathrm{CO}_{2}$ and other GHG emissions along the life cycles $\left(\mathrm{GWP}_{\text {other }}\right)$. These total GWPs are compared to GWP for a fossil $\mathrm{PE}$ route. All values are given in $\mathrm{tCO}_{2, \mathrm{eq}} / \mathrm{t} \mathrm{PE}$ produced

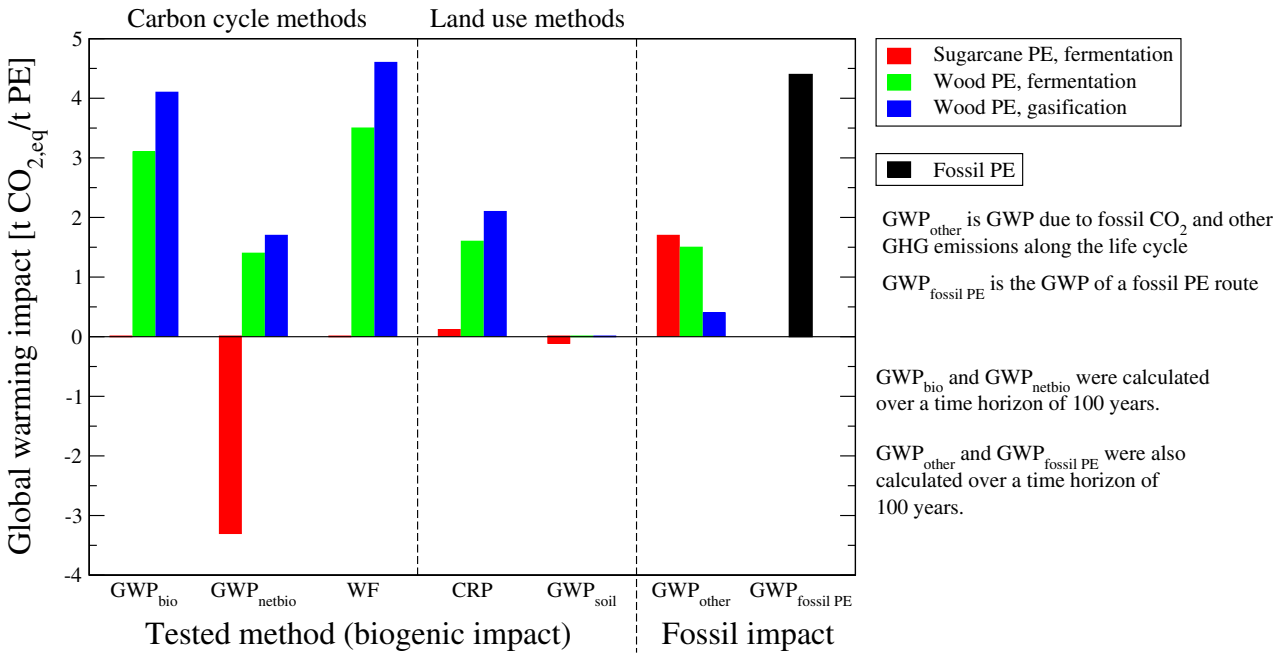


route's GWP from fossil $\mathrm{CO}_{2}$ and other GHGs $\left(\mathrm{GWP}_{\text {other }}\right)$, its impact becomes even bigger than that of the fossil alternative (4.5 and $5 \mathrm{t} \mathrm{CO}_{2, \mathrm{eq}} / \mathrm{t} \mathrm{PE}$ for the $\mathrm{GWP}_{\text {bio }}$ and WF methods, respectively, vs. $4.4 \mathrm{t} \mathrm{CO}_{2, \mathrm{eq}} / \mathrm{t} \mathrm{PE}$ for the fossil alternative). A similar effect was found for the wood fermentation route $\left(4.6\right.$ and $5 \mathrm{t} \mathrm{CO}_{2, \mathrm{eq}} / \mathrm{t} \mathrm{PE}$ for the $\mathrm{GWP}_{\mathrm{bio}}$ and WF methods, respectively). Only for the sugarcane route, the GWP does not increase using the $\mathrm{GWP}_{\text {bio }}$ or the WF methods and sugarcane becomes the preferable option in comparison to both the wood based and the fossil alternatives. The reason for the considerable impact of biogenic $\mathrm{CO}_{2}$ emissions within the wood routes when applying the $\mathrm{GWP}_{\text {bio }}$ and the WF methods is the way the methods handle the release and uptake of $\mathrm{CO}_{2}$ by biomass. They start with a full grown stand that is harvested and converted to products, which are eventually disposed of, causing emissions along the way. The re-growing plants eventually take up an equal amount of $\mathrm{CO}_{2}$. However, since this takes time, the atmospheric concentration of $\mathrm{CO}_{2}$ stays elevated and contributes to global warming. In the case of boreal wood, this re-growth takes around 100 years, causing an impact of 3-4 t $\mathrm{CO}_{2, \mathrm{eq}} / \mathrm{t} \mathrm{PE}$ using the $\mathrm{GWP}_{\text {bio }}$ and the WF methods. In contrast, the sugarcane grows very fast, leading to an almost instantaneous uptake of emissions and hence an impact close to $0 \mathrm{t} \mathrm{CO}_{2, \mathrm{eq}} / \mathrm{t} \mathrm{PE}$.

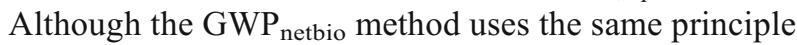
of temporal differences between $\mathrm{CO}_{2}$ release and uptake, it leads to a smaller total GWP for the wood routes (2.9 $\mathrm{t} \mathrm{CO}_{2, \mathrm{eq}} / \mathrm{t} \mathrm{PE}$ for the wood fermentation route and $2.1 \mathrm{t} \mathrm{CO}_{2, \text { eq }} / \mathrm{t} \mathrm{PE}$ for the wood fermentation route). This is due to the consideration of avoided fossil emissions, which disguises the impact from the temporal differences in release and uptake of $\mathrm{CO}_{2}$. As a consequence, despite their increase in GWP, the wood fermentation and gasification routes are still preferable in comparison to the fossil route. However, sugarcane is again the preferable option

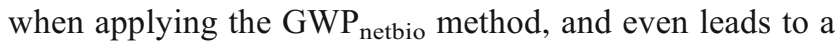
negative total GWP (-1.6 t $\left.\mathrm{CO}_{2, \mathrm{eq}} / \mathrm{t} \mathrm{PE}\right)$, again due to consideration of avoided fossil emissions.

To summarize, all three methods find the sugarcane route to be the better alternative for bio-based PE production. Furthermore, the results for the GWP $\mathrm{Gio}_{\text {bio }}$ and WF methods are similar to one another and make the wood-based cases similar to or worse than the fossil alternative. This similarity is due to PE packaging being a short-lived product. However, for long-lived products, results will differ between the two methods - see the discussion on temporary carbon storage (see Sect. 4.5) for more details. Finally, the GWP netbio method results in the same ranking for the biomass-based routes, but they have a significantly lower impact on global warming than the fossil route. This is due to the consideration of avoided fossil emissions in the $\mathrm{GWP}_{\text {netbio }}$ method. Moreover, the method also considers lost uptake, which together with avoided emissions cannot only lead to opaque results (if not well documented) but is also challenging to determine. This was particularly the case for the sugarcane based PE route. In our study, we estimated lost uptake for sugarcane to be close to zero. However, this estimate is not self-evident and could have been done differently, considering that the method was developed for forestry and provides no guidance on how to determine lost uptake for short rotation crops.

\subsection{Results for the land use methods}

According to the CRP method, all of the bio-based routes perform better than the fossil route (see Fig. 3). However, the sugarcane route performs significantly better than the two wood routes (1.6 and $2.1 \mathrm{tCO}_{2, \mathrm{eq}} / \mathrm{tPE}$ for the wood routes vs. $0.12 \mathrm{t} \mathrm{CO}_{2, \mathrm{eq}} / \mathrm{t} \mathrm{PE}$ for the sugarcane route). This is in line

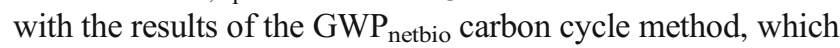
shows a similar impact for the wood based routes and a significantly smaller impact (even negative, in this case) for the sugarcane based route. The difference between the wood gasification and fermentation routes is explained by the fact that more wood is needed for the production of $1 \mathrm{t}$ of PE via gasification than via fermentation. For the wood routes, the impact is fully due to occupational land use, since it was assumed that the transformation took place a long time ago and is already amortized. Furthermore, since there is no change in soil organic carbon during occupation (Chen et al. 2010; De Simon et al. 2012), all impact is related to changes in above ground carbon stocks. The higher impact values, when compared to the sugarcane route, can be explained by the slower growth rate of a boreal forest, which determines the requirement for land area (i.e. the land occupation inventory flow). The assumed carbon uptake rate in Swedish forest $(1.1 \mathrm{t} \mathrm{C} /$ ha year) results in a land occupation flow of 0.9 ha year/t C. It should be noted however that regional differences occur: the actual carbon uptake rate (or forest growth rate) varies significantly between southern and northern Sweden (from $1.5 \mathrm{t} \mathrm{C} /$ ha.year in the south to $0.7 \mathrm{t}$ $\mathrm{C} /$ ha.year in the north) leading to large differences in the resulting land occupation flow (Swedish Forest Agency 2014) and thus in the CRP results. The results shown in Fig. 3 reflect an average value. The CRP method points out that the sugarcane route is preferable over both wood routes with regard to land use. This is in spite of the carbon losses from vegetation and soil $(58 \mathrm{t} \mathrm{C} / \mathrm{ha})$ during transformation (from Brazilian Cerrado, amortized over 20 year) and due to the fact that sugarcane has a much faster growth rate, resulting in a lower land occupation flow.

The results of the assessment with the GWP $\mathrm{Goil}_{\text {method }}$ show that there is no impact for the wood-based routes and they are preferable over the fossil PE route (Fig. 3). This is due to the assumptions that land transformation took place a long 
time ago and that there is no change in the soil organic carbon content in a well-managed forest due to harvest. The sugarcane route was even found to result in carbon sequestration during land use at $-0.11 \mathrm{t} \mathrm{CO}_{2, \mathrm{eq}} / \mathrm{t} \mathrm{PE}$ (transformation amortized over 20 years and occupation, taken together) (see Fig. 3 ), although the transformation from natural vegetation (Brazilian Cerrado) to sugarcane cultivation leads to a significant decrease in soil organic carbon content. However, due to carbon sequestration into the soil during the occupation (Anderson-Teixeira et al. 2009), this loss is compensated. Nevertheless, it would take close to 100 years to fully recover the soil organic carbon content due to this uptake. As a consequence, the choice of the amortization time of the land transformation impact may affect the impact result significantly. For example, if the land transformation impact was fully allocated to the first year of occupation, then the impact would be $+1.24 \mathrm{t} \mathrm{CO}_{2, \mathrm{eq}} / \mathrm{t}$ PE.

\section{Discussion}

This section discusses the methodological challenges encountered during the application of the land use and carbon cycle methods, building on the framework developed by Helin et al. (2013) (see Sect. 2.3). In addition, we also discuss the more practical applicability of the different methods tested.

\subsection{Reference states and reference points}

One of the methodological issues that has been brought forward for the assessment of land use and of time lags (as part of the carbon cycle methods) in LCA is the need to define a reference state. Reference states are used in all methods tested, however, more or less explicitly. In the methods underpinning the UNEP-SETAC guideline, here referred to as land use methods, the need for a reference state is made explicit and the guideline recommends the use of a biome-dependent (quasi-)natural state (Koellner et al. 2013) (p.1199). However, it is unclear whether this refers to $\mathrm{Q}_{\text {his }}$ (the historical land quality) or $\mathrm{Q}_{\text {rel }}$ (the land quality of the relaxed state) according to the terminology in Fig. 2. In comparison, Milà et al. (2007) recommend the relaxed state $\left(\mathrm{Q}_{\text {rel }}\right)$ as a reference state.

The determination of a reference state for land use was particularly challenging for the wood routes, since the carbon stock in the mature managed forest was found to be similar to the one for a mature natural forest. We found data stating that a mature, 100-year-old managed boreal forest has a carbon content of $40 \mathrm{t} / \mathrm{ha}$, while a 200 -yearold boreal forest has a carbon content of $50 \mathrm{t} / \mathrm{ha}$ (see Table 3). However, there is a variability in such data (not investigated in this paper). Since data for mature managed forests presumably are easier to find, it might be argued that the carbon stock in the mature managed forest could be used as a good enough approximation for the mature natural forest.

The carbon cycle methods also use reference states, even

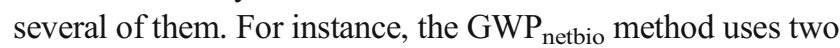
explicit references. One is the avoided alternative production of the product (see the description of the GWP netbio $_{\text {method in }}$ Sect. 2.2), in which case, the practitioner is left with the decision on which avoided alternative to model, e.g. whether it is a crude oil-based or a coal-based alternative. The other one is the reference needed to calculate the lost uptake, which would have occurred had the feedstock been left standing. The definition of the latter was particularly challenging for the sugarcane case. When interpreting the GWP ${ }_{\text {netbio }}$ for sugarcane, we chose to include lost uptake for 1 year of occupation assuming that the occupation prevents the first year of re-evolution to Cerrado. Expressed in the terminology of the land use methods, occupation postpones the relaxation back to Cerrado. However, this interpretation of the $\mathrm{GWP}_{\text {netbio }}$ is not self-evident and could have been done differently. For example, the lost uptake due to missed re-evolution could have been assessed at a later point during the relaxation process. However, the method description provides no guidance on how to determine lost uptake for short rotation crops, and maybe the method was never even intended to be used for short rotation crops.

In addition to the reference states, there is also a less explicit point of reference in all of the carbon cycle methods. All three methods start their assessment with the harvesting of a mature stand and model the re-growth to this state. For forestry, we argue that this means that the fully grown forest stand is used as point of reference. However, as for example pointed out by Levasseur et al. (2013), this is not a self-evident choice for the point of reference, but rather depends on the goal and scope of the assessment. In their study, Levasseur et al. (2013) propose to use a 'just beginning to grow' forest as the reference point for the assessment of afforestation and related production. The methods we have investigated choose the mature forest as a point of reference, without making the choice explicit. This is in contrast to the land use methods, which are explicit about the need for and use of reference states. The value-based choice of a reference point for the carbon cycle methods (e.g. the choice between the fully mature forest or the just beginning to grow forest) can therefore be debated.

Since the definition of a reference state or point of reference is necessary for the land use and carbon cycle methods to obtain assessment results, the most applicable approach for a practitioner, for now, is the explicit statement of his/her choice. This promotes transparency and enables discussions about results with stakeholders, a process which eventually might lead to the development of conventions. 


\subsection{Spatial system boundaries-stand versus landscape approach}

Related to the choice of the point of reference for the carbon cycle methods is the debate whether to use a stand or a landscape approach. All three tested methods use a stand approach, i.e. what is being considered is re-growth on the same plot as where biomass was harvested (see also the description of the GWP bio method in Sect. 2.2). An alternative approach for managed forests would be to use a landscape approach, which could be done in two ways:

(1) The managed and steady-state forest landscape is compared with a state of independent evolution (Helin et al. 2013; Ros et al. 2013), or

(2) The ongoing $\mathrm{CO}_{2}$ uptake of not yet harvested plots is allocated to the preceding harvest on that same plot rather than used to offset the carbon emissions of a newly harvested neighbouring plot (Cherubini et al. 2013). Cherubini et al. (2013) demonstrate that this approach leads to identical results at the forest stand and landscape levels. This approach implies use of the mature forest as a reference, also at a landscape level.

Recently, Cintas et al. (2017) demonstrated that the results of assessment at the landscape level depend on how the spatial system boundaries are defined, that is, whether these boundaries are constant or are expanding during an accounting period. Cintas et al. (2017) argue that using constant spatial boundaries is preferred because in that case all carbon flows in a landscape are accounted for and thus is a true landscape approach. This is contrary to Cherubini et al. (2013) (see (2) above) who assume that the spatial system boundaries expand during the accounting period (by offsetting the carbon emissions of a newly harvested plot) and thus account for all carbon flows in the landscape only at the end of an accounting period when all stands that comprise the landscape are included in the assessment.

\subsection{Approaches towards time in land use and carbon cycle methods}

Another methodological difference found between the carbon cycle and land use methods is the way time is considered. The carbon cycle methods are time-dependent. Particularly for the calculation of the $\mathrm{GWP}_{\text {bio }}$ and the GWP $\mathrm{Getbio}_{\text {in }}$ characterization factors, the consideration of the actual timing of carbon release and uptake is at the core of the method. The WF method is less time-dependent, since it considers the carbon release as occurring at the time of harvest, instead of during the rest of the life cycle.

In comparison, the land use methods have a static approach, using time as a means to distribute emissions due to transformation over several consecutive harvests through amortization, without any actual consideration of timing. For example, the $\mathrm{GWP}_{\text {soil }}$ as described by Brandão et al. (2011) amortizes emissions from land transformation over 100 years of production, a choice which appears as value laden as any other amortization period currently presented in the literature (see e.g. Cederberg et al. (2011)). It should be noted that the $\mathrm{GWP}_{\text {soil }}$ method differs from the UNEP-SETAC guideline (Koellner et al. 2013) in that it accounts for the carbon flows during the time of occupation, instead of accounting for delayed relaxation. Moreover, the CRP method uses a time horizon of 500 years to determine the climate impact of $\mathrm{CO}_{2}$ emissions (i.e. the $\mathrm{GWP}_{500}$ ), which seems rather arbitrary, in particular when considering the argument provided for this choice, namely that shorter time horizons would make land use look worse. The CRP method also does not explicitly treat the issue of how to amortize or allocate the impact of land transformation to several consecutive years of occupation, which is needed to operationalize the method. Milà et al. (2013), who used the CRP method in a case study, applied an amortization period of 20 years, which is also recommended by the UNEP-SETAC guideline (Koellner et al. 2013).

\subsection{Carbon pools considered}

The issue of which carbon pools to consider in the assessment is another methodological challenge, at least for the carbon cycle methods. There is no clear description on which carbon pools to consider for these methods, and which ones are considered seems to be an issue of data availability. For example, Cherubini et al. (2012) consider both the below and above ground carbon, including the carbon in growing, as well as decaying biomass (e.g. forest residues left on site). However, this type of data might not be available for every case.

The land use methods tested give more clear directions. The CRP method takes above as well as below ground carbon pools into consideration. The $\mathrm{GWP}_{\text {soil }}$ method only considers soil carbon, however without any claim that this would fully account for the carbon balances of cultivation. Rather, Brandão et al. (2011) use the results of this method as a complement to a standard life cycle carbon balance in order to obtain a more complete picture of the carbon flows occurring in the system under study. It should be noted that the computational framework described in the UNEP-SETAC guideline assumes that land quality, which can be measured with the soil organic carbon content, stays constant during the time of occupation. However, the guideline acknowledges that land quality is not always constant during occupation (Koellner et al. 2013, p.1198, and indicated in Fig. 2 in this paper). 


\subsection{Temporary carbon storage in products}

An issue particular for the carbon cycle methods is the consideration of temporary carbon storage in products, which is handled differently among the methods. For example, the WF method does not account for storage in products but models an immediate oxidation of the product (in our case study, the incineration of PE), co-occurring with the harvest. This implies that the life span of the product is ignored (or is set to 0 ). This makes the WF method less suitable for the assessment of, e.g. forest products used in construction which typically have a life span of many years. In contrast, the GWP netbio $_{\text {and the }}$ $\mathrm{GWP}_{\text {bio }}$ methods consider when in time the product oxidises and cut-off emissions occur past the time horizon under assessment. The latter resembles the approach of the Lashof method, which is one of the methods used to assess temporary carbon storage in LCA (Levasseur et al. 2012). Including the timing of product oxidation arguably increases the adequacy of the assessment because a more realistic description of the life cycle of the product is used. When cutting off emissions at the time horizon of the assessment, this delay in the emission, or temporary storage, of carbon in a product leads to a lower impact during the accounting period.

\subsection{Application challenges}

A practical challenge encountered for all methods was data availability. Especially, for the application of the $\mathrm{GWP}_{\text {netbio }}$ method to the sugarcane PE route, data that would represent the re-evolution of a sugarcane field back to natural vegetation in a continuous manner could not be found, and a simplified estimate needed to be made. This is potentially not only an issue for sugarcane, but for short rotation crops in general. Therefore, although outside the scope of this study, further and more extended searches are recommended to explore potential data sources. Another challenge connected to data is their quality and consistency. For example, considering above- as well as belowground carbon could have a considerable influence on assessment results (Cherubini et al. 2012). Therefore, consistent and qualitatively comparable data are a necessary prerequisite to ensure the comparability of studies.

Considerable computational effort and related time needs were an issue for implementing the $\mathrm{GWP}_{\text {bio }}$ and the $\mathrm{GWP}_{\text {netbio }}$ methods. On the one hand, this might not be justifiable for everyday use where time is limited and pre-calculated characterization factors are an essential part of the LCA analyst's toolbox. On the other hand, as pointed out by Helin et al. (2013), the use of already provided factors might not be suitable for every purpose, as conditions might be very different. For this reason, over the medium term, the calculation and provision of characterization factors for a broad spectrum of conditions might be worthwhile in order to foster the impact assessment of biogenic $\mathrm{CO}_{2}$.
In addition, the acceptance of the assessment methods is a challenge related to application as well. We presented LCA results based on the tested methods to both industrial stakeholders and researchers developing biomass-based technology. They were rather sceptical towards the methods and questioned the results. Especially the carbon cycle methods were debated, in particular the single stand approach and use of the mature forest as a reference point. Both choices are clearly value laden and methodology developers should be open to discussion about them with other stakeholders. Moreover, there is the risk that if assessment methods are not accepted as legitimate or scientifically sound, they are not likely to be acted upon. Nevertheless, the need for discussion should be no excuse for not using debated methods, since they can help identifying new, potential environmental hotspots, which otherwise might develop to substantial threats.

\section{Conclusions}

When testing the different methods on the case studies, it was found that the choice of method influences the ranking of the biomass-based routes among each other (see Fig. 3), as well as in relation to an equivalent fossil based product. This shows that although methods are available for assessing the impact of carbon flows from biomass-based products in LCA, their outcome is variable and hence not yet robust. Some of the variability depends on variability in data, but most of it is due to differences in methodology. Furthermore, our study has proven that it is possible to find data to apply the methods; however, the effort was considerable. Moreover, we found the workload to apply the methods to be quite variable, with some methods being fairly work extensive.

We suggest that method developers strive to reconcile the different approaches suggested, with regard to the following aspects:

Consideration of time. Time differences between uptake and release of carbon need to be considered in LCIA methods for biogenic carbon flows. Currently, such time differences are considered only in what we here have called the carbon cycle methods, but not in the methods here called land use methods. Furthermore, there are still unresolved issues regarding amortization periods (although recommendations exist, see Sect. 4.3) and regarding what time horizons are used to assess the global warming potential of biogenic carbon emissions.

Applicability to short and long rotation crops. The LCIA methods for biogenic carbon flows need to be applicable equally well to short rotation and long rotation crops, which is related to their consideration of time. If for no other reason, this is because LCAs of biomass-based 
products often compare products from different types of feedstock. Our case study showed that the application of carbon cycle methods to short rotation crops was open to interpretation, and hence, the results were not robust, which is why developers of carbon cycle methods in particular need to consider the methods' applicability to short rotation crops.

Coherent terminology and methodology aligned with general LCIA frameworks. More work is needed to arrive at a coherent terminology and set of concepts in the field, although it is recognized that the work leading up to the UNEP-SETAC guideline (Koellner et al. 2013) has included such efforts. For instance, there is a need to incorporate the issue of time lags between uptake and release of carbon into a more general framework for LCIA of land use activities. In addition, there are many terms used in the field that (presumably) have the same meaning, or roughly the same meaning, such as foregone sequestration, delayed relaxation and re-evolution. Work on definitions and translations between concepts would help to further the development of the field. Moreover, a stricter adherence to general LCIA frameworks would be valuable and make the methods easier to interpret by LCA analysts. For example, elements normally belonging to the inventory phase of LCA should preferably not be built into LCIA methods (as the GWP netbio method does). It would also be helpful if the characterization factors that are calculated using the methods are more clearly defined and explicitly spelled out as such.

Value laden methodological choices. As any LCIA method, the tested LCIA methods include valueladen choices. For LCIA of carbon flows related to biomass production and use, the choice of reference state(s) is one such choice of particular importance. For example, while being very clear about the need for a reference state, the UNEP-SETAC guideline (Koellner et al. 2013) is less clear about what state to use exactly. A similar issue also applies to the $\mathrm{GWP}_{\text {netbio }}$ and the reference state for lost uptake, in particular for short rotation crops. Other points of reference used by the carbon cycle methods are less explicit. This applies in particular to the fact that all the carbon cycle methods tested here start their assessment with the harvesting of a mature stand and model the regrowth to this state. We argue that this means that the fully grown forest stand is used as point of reference and that this needs to be clearly stated. We recognize that LCIA methods cannot be constructed without making value laden methodological choices, and recommend method developers to be explicit about them. We also recommend methods to be tested using different modelling choices regarding starting points, e.g. a fully grown forest vs. a forest that starts to grow.
Stakeholder involvement. Finally, the choice of reference states and other value laden methodological choices need to be discussed with stakeholders in the field, including land owners, policy makers, industrial stakeholders, NGOs, as well as experts from the fields the LCIA methods draw on. Otherwise, there is a risk that stakeholders feel excluded and might simply ignore and hence not act upon assessments. Even though such discussions might not lead to consensus, they will pave the way for informed choices of reference states and other value laden elements of the methods, and possibly with time and experience, the development of conventions.

Open Access This article is distributed under the terms of the Creative Commons Attribution 4.0 International License (http:// creativecommons.org/licenses/by/4.0/), which permits unrestricted use, distribution, and reproduction in any medium, provided you give appropriate credit to the original author(s) and the source, provide a link to the Creative Commons license, and indicate if changes were made.

\section{References}

Agostini A, Giuntoli J, Boulamanti A (2013) Carbon accounting of forest bioenergy, conclusions and recommendations from a critical literature review. Tech. Rep. Report EUR 25354 EN. Joint Research Centre, Institute for Energy and Transport, European Commission, Ispra, Italy

Anderson-Teixeira KJ, Davis SC, Masters MD, Delucia EH (2009) Changes in soil organic carbon under biofuel crops. GCB Bioenergy 1(1):75-96. https://doi.org/10.1111/j.1757-1707.2008. 01001.x

de Baan L, Alkemade R, Koellner T (2013) Land use impacts on biodiversity in LCA: a global approach. Int J Life Cycle Assess 18(6): 1216-1230. https://doi.org/10.1007/s11367-012-0412-0

de Baan L, Curran M, Rondinini C, Visconti P, Hellweg S, Koellner T (2015) High-resolution assessment of land use impacts on biodiversity in life cycle assessment using species habitat suitability models. Environ Sci Technol 49(4):2237-2244. https://doi.org/10.1021/ es504380t

Berg S, Lindholm EL (2005) Energy use and environmental impacts of forest operations in Sweden. J Clean Prod 13(1):33-42. https://doi. org/10.1016/j.jclepro.2003.09.015

Bernier P, Paré D (2013) Using ecosystem CO2 measurements to estimate the timing and magnitude of greenhouse gas mitigation potential of forest bioenergy. GCB Bioenergy 5(1):67-72. https://doi.org/10. 1111/j.1757-1707.2012.01197.x

Brandão M, Milà i, Canals L, Clift R (2011) Soil organic carbon changes in the cultivation of energy crops: implications for GHG balances and soil quality for use in LCA. Biomass Bioenergy 35(6):23232336. https://doi.org/10.1016/j.biombioe.2009.10.019

de Carvalho Macedo I, Leal MRLV, da Silva JEAR (2004) Assessment of greenhouse gas emissions in the production and use of fuel ethanol in Brazil. Tech Rep, Secretariat of the Environment, Government of the State of Sao Paulo, Sao Paulo

Cederberg C, Persson UM, Neovius K, Molander S, Clift R (2011) Including carbon emissions from deforestation in the carbon 
footprint of Brazilian beef. Environ Sci Technol 45(5):1773-1779. https://doi.org/10.1021/es103240z

Chen J, Colombo SJ, Ter-Mikaelian MT, Heath LS (2010) Carbon budget of Ontario's managed forests and harvested wood products, 20012100. For Ecol Manag 259(8):1385-1398. https://doi.org/10.1016/j. foreco.2010.01.007

Cherubini F, Peters GP, Berntsen T, Strømman AH, Hertwich E (2011b) $\mathrm{CO}_{2}$ emissions from biomass combustion for bioenergy: atmospheric decay and contribution to global warming. GCB Bioenergy 3(5): 413-426. https://doi.org/10.1111/j.1757-1707.2011.01102.x

Cherubini F, Strømman AH, Hertwich E (2011a) Effects of boreal forest management practices on the climate impact of $\mathrm{CO}_{2}$ emissions from bioenergy. Ecol Model 223(1):59-66. https://doi.org/10.1016/j. ecolmodel.2011.06.021

Cherubini F, Bright RM, Strømman AH (2012) Site-specific global warming potentials of biogenic $\mathrm{CO}_{2}$ for bioenergy: contributions from carbon fluxes and albedo dynamics. Environ Res Lett 7(4): 045-902

Cherubini F, Guest G, Strømman AH (2013) Bioenergy from forestry and changes in atmospheric $\mathrm{CO}_{2}$ : reconciling single stand and landscape level approaches. J Environ Manag 129:292-301. https://doi.org/10. 1016/j.jenvman.2013.07.021

Cintas O, Berndes G, Cowie AL, Egnell G, Holmström H, Ågren GI (2015) The climate effect of increased forest bioenergy use in Sweden: evaluation at different spatial and temporal scales. WIREs Energy Environ 5(3):351-369. https://doi.org/10.1002/ wene. 178

Cintas O, Berndes G, Cowie AL, Egnell G, Holmström H, Marland G, Ågren GI (2017) Carbon balances of bioenergy systems using biomass from forests managed with long rotations: bridging the gap between stand and landscape assessments. GCB Bioenergy 9(7): 1238-1251. https://doi.org/10.1111/gcbb.12425

De Simon G, Alberti G, Delle Vedove G, Zerbi G, Peressotti A (2012) Carbon stocks and net ecosystem production changes with time in two Italian forest chronosequences. Eur J Forest Res 131(5):12971311

Ericsson N, Porsö C, Ahlgren S, Nordberg Å, Sundberg C, Hansson PA (2013) Time-dependent climate impact of a bioenergy system methodology development and application to Swedish conditions. GCB Bioenergy 5(5):580-590. https://doi.org/10.1111/gcbb.12031

European Environment Agency (2012) European waters - current status and future challenges - a synthesis. Tech. Rep. EEA Report No 9/2012, European Environment Agency, Copenhagen. https://doi. org/10.2800/63931

de Figueiredo E, Panosso A, Romão R, La Scala J Newton (2010) Greenhouse gas emission associated with sugar production in southern Brazil. Carbon Balance Manag 5(1):3. https://doi.org/10.1186/ 1750-0680-5-3

Food and Agricultural Organization of the United Nations (2014) Faostat domains. URL http://faostat3.fao.org/faostat-gateway/go/to/ download/R/RL/E Accessed 13 March 2014

Geyer R, Lindner JP, Stoms DM, Davis FW, Wittstock B (2010a) Coupling GIS and LCA for biodiversity assessments of land use. Int J Life Cycle Assess 15(7):692-703. https://doi.org/10.1007/ s11367-010-0199-9

Geyer R, Stoms DM, Lindner JP, Davis FW, Wittstock B (2010b) Coupling GIS and LCA for biodiversity assessments of land use. Int J Life Cycle Assess 15(5):454-467. https://doi.org/10.1007/ s11367-010-0170-9

Goglio P, Smith WN, Grant BB, Desjardins RL, McConkey BG, Campbell CA, Nemecek T (2015) Accounting for soil carbon changes in agricultural life cycle assessment (LCA): a review. J Clean Prod 104:23-39. https://doi.org/10.1016/j.jclepro.2015.05. 040

Helin T, Sokka L, Soimakallio S, Pingoud K, Pajula T (2013) Approaches for inclusion of forest carbon cycle in life cycle assessment-a review. GCB Bioenergy 5(5):475-486. https://doi.org/10.1111/ gcbb.12016

Helin T, Holma A, Soimakallio S (2014) Is land use impact assessment in LCA applicable for forest biomass value chains? Findings from comparison of use of Scandinavian wood, agro-biomass and peat for energy. Int J Life Cycle Assess 19(4):770-785. https://doi.org/ 10.1007/s11367-014-0706-5

Holtsmark B (2012) Harvesting in boreal forests and the biofuel carbon debt. Clim Chang 112(2):415-428. https://doi.org/10.1007/s10584011-0222-6

International Organization of Standardization (2006) Environmental management-life cycle assessment — principles and framework (ISO 14040)

IPCC (2013) Climate change 2013: the physical science basis Contribution of Working Group I to the Fifth Assessment Report of the Intergovernmental Panel on Climate Change. Cambridge University Press, Cambridge and New York

Kløverpris J, Mueller S (2013) Baseline time accounting: considering global land use dynamics when estimating the climate impact of indirect land use change caused by biofuels. Int J Life Cycle Assess 18(2):319-330. https://doi.org/10.1007/s11367-012-0488-6

Koellner T, Baan L, Beck T, Brandão M, Civit B, Margni M, Milà I, Canals L, Saad R, Maia de Souza D, Müller-Wenk R (2013) UNEP-SETAC guideline on global land use impact assessment on biodiversity and ecosystem services in LCA. Int J Life Cycle Assess 18(6):1188-1202. https://doi.org/10.1007/s11367-013-0579-z

Koponen K, Soimakallio S (2015) Foregone carbon sequestration due to land occupation - the case of agro-bioenergy in finland. Int J Life Cycle Assess 20(11):1544-1556. https://doi.org/10.1007/s11367015-0956-X

Lamers P, Junginger M (2013) The 'debt' is in the detail: a synthesis of recent temporal forest carbon analyses on woody biomass for energy. Biofuels Bioprod Biorefin 7(4):373-385. https://doi.org/10. 1002/bbb.1407

Levasseur A, Brandao M, Lesage P, Margni M, Pennington D, Clift R, Samson R (2012) Valuing temporary carbon storage. Nat Clim Chang 2(1):6-8

Levasseur A, Lesage P, Margni M, Samson R (2013) Biogenic carbon and temporary storage addressed with dynamic life cycle assessment. J Ind Ecol 17(1):117-128. https://doi.org/10.1111/j.15309290.2012.00503.x

Lindeijer E (2000) Review of land use impact methodologies. J Clean Prod 8(4):273-281. https://doi.org/10.1016/S0959-6526(00)00024$\mathrm{X}$

Liptow C, Tillman AM (2012) A comparative life cycle assessment study of polyethylene based on sugarcane and crude oil. J Ind Ecol 16(3): 420-435. https://doi.org/10.1111/j.1530-9290.2011.00405.x

Liptow C, Tillman AM, Janssen M, Wallberg O, Taylor G (2013) Ethylene based on woody biomass: what are environmental key issues of a possible future Swedish production on industrial scale. Int J Life Cycle Assess 18(5):1071-1081. https://doi.org/10.1007/ s11367-013-0564-6

Liptow C, Tillman AM, Janssen M (2015) Life cycle assessment of biomass-based ethylene production in Sweden - is gasification or fermentation the environmentally preferable route? Int J Life Cycle Assess 20(5):632-644. https://doi.org/10.1007/s11367-015-0855-1

Milà I, Canals L, Bauer C, Depestele J, Dubreuil A, Gaillard RFKG, Michelsen O, Müller-Wenk R, Rydgren B (2007) Key elements in a framework for land use impact assessment within LCA. Int J Life Cycle Assess 12(1):5-15. https://doi.org/10.1065/lca2006.05.250

Milà i, Canals L, Rigarlsford G, Sim S (2013) Land use impact assessment of margarine. Int J Life Cycle Assess 18(6):1265-1277. https:// doi.org/10.1007/s11367-012-0380-4

Muñoz I, Flury K, Jungbluth N, Rigarlsford G, Milà I, Canals L, King H (2014) Life cycle assessment of bio-based ethanol produced from 
different agricultural feedstocks. Int J Life Cycle Assess 19(1):109119. https://doi.org/10.1007/s11367-013-0613-1

Müller-Wenk R, Brandão M (2010) Climatic impact of land use in LCA — carbon transfers between vegetation/soil and air. Int J Life Cycle Assess 15(2):172-182. https://doi.org/10.1007/s11367-0090144-y

Pingoud K, Ekholm T, Savolainen I (2012) Global warming potential factors and warming payback time as climate indicators of forest biomass use. Mitig Adapt Strateg Glob Chang 17(4):369-386. https://doi.org/10.1007/s11027-011-9331-9

Pingoud K, Ekholm T, Soimakallio S, Helin T (2015) Carbon balance indicator for forest bioenergy scenarios. GCB Bioenergy 8(1):171182

Ros JP, van Minnen JG, Aerts EJ (2013) Climate effects of wood used for bioenergy. Tech. Rep. PBL Publication no. 1182, Alterra report no. 2455. PBL/Alterra, The Hague/Bilthoven, The Netherlands
Schmidt JH, Weidema BP, Brandão M (2015) A framework for modelling indirect land use changes in life cycle assessment. J Clean Prod 99: 230-238. https://doi.org/10.1016/j.jclepro.2015.03.013

Swedish Forest Agency (2014) Skogsstatistisk årsbok 2014 (Swedish statistical yearbook of forestry). Swedish Forest Agency, Linköping

Väisänen S, Valtonen T, Soukka R (2012) Biogenic carbon emissions of integrated ethanol production. Int J Energy Sect Manag 6(3):381396. https://doi.org/10.1108/17506221211259682

Zanchi G, Pena N, Bird N (2012) Is woody bioenergy carbon neutral? A comparative assessment of emissions from consumption of woody bioenergy and fossil fuel. GCB Bioenergy 4(6):761-772. https://doi. $\operatorname{org} / 10.1111 / j .1757-1707.2011 .01149 . x$ 